\title{
Biomimetics and its tools
}

1 Kristina Wanieck Dipl.-Biol.*

PhD Candidate, Technology Campus Freyung, Deggendorf Institute of Technology, Freyung, Germany; Biogenic Polymers, Department of Life Science Engineering, Technische Universität München, Straubing، Germany

2 Pierre-Emmanuel Fayemi PhD

Consultant, Laboratory of Product Development and Innovation, Arts et Métiers ParisTech, Paris, France
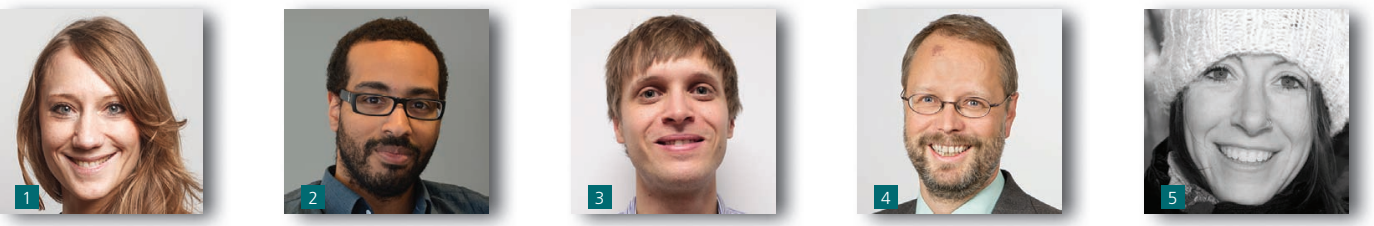

Biomimetics, as the transfer of strategies from biology to technology, is an emerging research area and has led to significant concepts over the past decades. The development of such concepts is described by the process of biomimetics, encompassing several steps. In Practice, beneficiaries of the process face challenges. Therefore, to overcome challenges and to facilitate the steps, tools have been developed in various areas, such as engineering, computing and design. However, these tools are not widely used yet. This paper presents an overview and a classification study of more than $\mathbf{4 0}$ tools with qualitative criteria. The criteria included, for example, the year of development, the accessibility of tools, the facilitated steps of the process or their contribution to sustainability. The classification shows that certain steps of the process and their challenges are well addressed by the tools, while other steps are not. The presented results contribute to the proposal of an improvement of the state of the art, and they build the foundation for future theoretical and practical analyses. These findings could contribute to increasing the implementation of biomimetics in various disciplines in the long term.

\section{Introduction}

Biomimetics applies principles and strategies from biological systems to engineering and technological products, processes and design in general. The potential of biomimetics is considered to be boundless, ${ }^{1}$ and its significant scientific, societal and economic impacts will have benefits to the quality of life. ${ }^{2}$ The rate of research publications on biomimetics has been increasing over the past years and has reached nearly 3000 papers per year, indicating that biomimetics is becoming a dominant paradigm for various technological disciplines, such as robotics and material sciences. ${ }^{2}$ On the other hand, the number of commercially available biomimetic products is rather low (of 303 biomimetic cases, 28\% are commercially available, $60 \%$ are in development, $8 \%$ are concepts and $2 \%$ are discontinued). ${ }^{3}$

\subsection{Challenges for biomimetics in practice}

According to Jacobs et al., ${ }^{3}$ some of the reasons which account for the small number of biomimetic products on the market is the lack of a clear method, ${ }^{4}$ the difficulties of interdisciplinary work and the complexity of biology as a model. In line with these aspects, studies on teaching students in biomimetics have shown key challenges with the process - that is, communication across discipline boundaries, analysis of problems to solve and identification and understanding of biological systems. ${ }^{5,6}$ Obviously, the process of biomimetics reveals gaps and challenges in Practice (Figure 1). Practice is referenced in this paper as the use of biomimetics for product development and idea generation, focused on the industrial context. In order to generate appropriate biomimetic design concepts with a potential for commercialisation, these gaps need to be overcome.

Significant research has been carried out to facilitate the systematic transfer of biological knowledge to technology and to present methods (e.g. Badarnah and $\mathrm{Kadri}^{7}$ ) to create tools which will ultimately facilitate the biomimetic process. ${ }^{8}$ These tools can then be used in Practice as described earlier. Tools for biomimetics are referenced in this paper as means to be used in performing or supporting the biomimetic process or parts thereof. A method is referred to in the following as a way of accomplishing a task during the process of biomimetics - for example, describing biological systems (for instance, with the Four-Box method $^{9}$ ) or analogy mapping of biological and technological systems (for instance, with the T-chart ${ }^{9}$ ). The process of biomimetics is described as a series of 


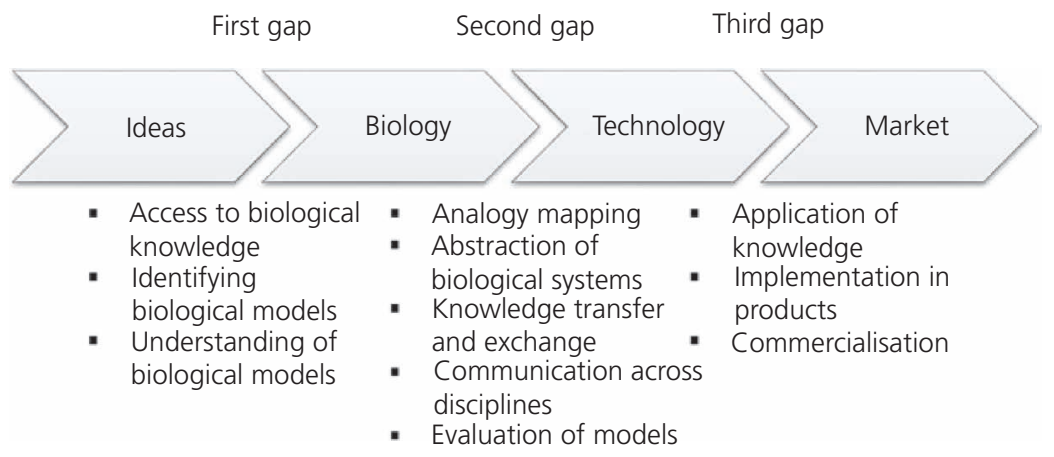

Figure 1. Gaps in the biomimetic design process and their underlying challenges $3,5,6$

steps - that is, actions, tasks and operations - leading to a biologically inspired design. If this design fulfils the three criteria for the definition of a biomimetic product ${ }^{10}$ (which are $(a)$ function analysis of a biological system, $(b)$ abstraction from the system to a model and (c) transfer and application without using the biological system), it is considered not only to be biologically inspired, but also to be biomimetic. Different overall process descriptions of biomimetics which describe the phases of the process in Practice for example, BioGen ${ }^{7}$ or the Biomimicry DesignLens ${ }^{11}$ (see also Fu et $a l^{1}{ }^{1}$ ) - are not included in the overview. It should be clarified that several publications exist which describe the implementation of biological principles, patterns or systems in technology - for example, Arzt, ${ }^{12}$ Meyers et al., ${ }^{13}$ Naleway et al., ${ }^{14}$ Wegst et al., ${ }^{15}$ Barthelat ${ }^{16,17}$ and Chen et al. ${ }^{18}$ These publications certainly describe the process of applying biomimetics, but they rather differ from what the authors consider a tool, as they address a specific topic and not the process of biomimetics in general. This means that these processes can be used for a specific goal, but they do not describe a mean which facilitates the problem-driven approach to any possible problem. In this paper, a tool is clearly to be distinguished from a general biomimetic practice, which can be, for example, a field of research or development in the context of biomimetics. A tool is something differentiated with variables v1 and v2 (see Section 2.2) and is used in performing the different steps and underlying tasks of the biomimetic process in general. A tool also enables users to overcome the challenges that they face during the process (see Figure 1). For instance, AskNature ${ }^{19,20}$ is a tool which overcomes the first gap of the process by offering a database for identifying biological models. In contrast, the description of, for example, nextgeneration materials ${ }^{16}$ is not considered to be a tool, as it does not facilitate the process of biomimetics for any given problem. It is rather a presentation of biological knowledge useful for biomimetic developments, which is of value for sure in solving engineering problems in the context of materials. But if what is aimed is, for example, opening and closing mechanisms in nature, such source of information does not help to identify biological models for the given problem. In order to identify tools in the context of this paper, the distinction has been made as described. The authors are aware that there is literature and research going on which offer valuable knowledge on biomimetics. Furthermore, the field of biomimetics and its community is very broad and many actors are involved in the topic. ${ }^{2,21,22}$ The aim of this paper is to focus on tools in particular; therefore, any research which did not fit the earlier mentioned definition is not considered.

Most of the existing tools have been described in the scientific literature, but were not widely used in the design of the 303 cases included in the BioM database. ${ }^{3}$ Furthermore, as the research community is fragmented and involves many disciplines, ${ }^{2,22}$ the development of these tools originates from different communities (such as the fields of scientific biomimetics, mechanical engineering, design, architecture, sustainability, creativity and innovation) with diverse areas of interest, research priorities and knowledge transfer practices. Although this diversity of disciplines contributes to the potential of biomimetics as an interand transdisciplinary approach, the knowledge and research findings are dispersed throughout academic, patent and popular literature.

Several notable publications have already summarised a subset of tools (e.g. Fu et al., ${ }^{1}$ Vincent et al., ${ }^{4}$ Stone et al., ${ }^{22}$ Glier et al., ${ }^{23}$ Goel et al., ${ }^{24}$ Nagel and Stone $^{25}$ ), reviewed biomimetics for different users - that is, the scientific community ${ }^{2}$ - carried out analytical studies with students (e.g. Helms et al., ${ }^{5}$ Yen et al. ${ }^{6}$ ) or provided case studies of existing products. ${ }^{3}$ But so far, no general overview of existing tools from the different disciplines and communities exists. Additionally, little work has focused on theoretical analysis of tools (see Fu et al., ${ }^{1}$ Fayemi et al. ${ }^{26}$ ), and the development of highly effective tools which assist designers is emphasized. ${ }^{27}$ It is therefore one aim of the present paper to give an overview of more than 40 existing tools which have been developed to facilitate and support biomimetics.

Furthermore, the results of a qualitative classification analysis are presented. The authors consider such a classification a way to gain insight about reasons for the lack of broad access. One reason for this lack could be the mere absence of knowledge about existing tools, indicating a communication gap between research and development. Another reason could be the lack of training and dissemination once tools are known. If one considers the various 
beneficiaries of biomimetics, it is almost impossible to train each of them in specific tools by the developers themselves. And one could assume that people interested in the topic might not have the skills necessary to access the scientific literature fully. Therefore, an overview of tools combined with a first approach of classifying and analysing them as a contribution to overcome the earlier mentioned gaps is highly needed. The presented theoretical analysis is an exploratory classification of existing tools. It does not test a specific hypothesis; instead, the aim is to use the data to build the foundation for further investigation and to establish hypotheses. This is a work in progress, and it will be combined with practical and further theoretical analyses. The authors also aim to clarify the beneficiaries of biomimetics. In general, biomimetics can be used in both the academia and industry, and the knowledge transfer from the academic field to the industrial application is key to foster success stories. Little research has focused on an audience analysis of biomimetics to identify differences in teaching and training methods. Furthermore, the development of tools did not differentiate potential users - that is, to raise the question of whether students might need tools other than those used by the designers from the industry. The authors consider this a necessary field of research, which is ongoing, but the presented analysis of tools may help to identify tools specific for certain target groups and how they can use appropriate tools for their own projects. The results presented are considered to be a state of the art of the existing tools, which will evolve in the future by including further and upcoming new tools.

\section{Methods}

\subsection{Identification of existing tools}

To identify existing tools of biomimetics, a literature review was carried out. A variety of search terms, including 'biomimetics', 'biomimicry, 'bioinspiration', 'biologically inspired design' and 'bionics', in combination with the search term 'tool', were used to screen the literature. The use of general Web-based resources for journals and conferences were not helpful for several reasons.

- The tools of interest derive from several disciplines; therefore, diverse operational terms are used which scatter the literature.

- So far, no commonly used or standard keywords exist for tools in particular to enable the identification of appropriate literature.

- Therefore, although several search terms were tested, the results of a text-based search were not satisfactory - that is, known literature about tools was not discovered.

- Some tools are not described in the scientific literature.

In order to identify as many tools as possible, most of the tools were gathered by hand by using the snowball principle. The focus of this study was the identification of tools that specifically address the process of biomimetics and not, for instance, other creativity tools which could be used for the process of biomimetics as well, but which were originally developed for other purposes. As biomimetics spans several fields of application, the authors did not narrow down the search by discipline from which the tools were derived or for which field of application their use was intended. Therefore, the identified tools and methods presented are the results of this search, and there was no further differentiation about, for example, the maturity of the respective tools. The authors emphasise the following limitations of the search approach. First, as the search was carried out by hand, the overview is not considered to be exhaustive. Second, some tools clearly labelled as designed for biomimetics or in the context of biomimetics - for example, by their title or description - were included in the overview, even though their content was not described in the scientific literature (e.g. Biologically Inspired Problem Solving (BiOPS) ${ }^{28}$ ). These tools were identified through general Web searches or were known by the authors due to their background and their networks. Third, as some tools which were added to the overview are available only in German, it is to be expected that other tools may exist in a language not manageable by the authors, and therefore, they were overlooked. These are unavoidable limitations of the information that is currently available; however, the authors assume the presented set of tools, designed for biomimetics, to be representative.

\subsection{Qualitative analysis: definition of variables and classification of tools}

Although existing tools and methods have been described and compared in the literature (e.g. Fu et al., ${ }^{1}$ Stone et al., ${ }^{22}$ Glier et al., ${ }^{23}$ Goel et al., ${ }^{24}$ Nagel and Stone ${ }^{25}$ ), a comparative evaluation of existing biomimetic tools has been described in only two publications. Fu et al. ${ }^{1}$ described six biologically inspired design methods and tools and differentiated between cognitive and implementation factors. They pointed out whether the respective factors are well addressed by the tools or whether there is an opportunity to address them. Fayemi et al. ${ }^{26,29}$ evaluated existing tools by using workshops. They used theoretical and practical indicators to evaluate the use of tools.

In order to contribute to a deeper understanding of existing tools, a qualitative analysis has been performed in this work. The authors focused on a descriptive analysis of the identified tools and the classification of implementation factors. This classification establishes the foundation for further theoretical analyses, which will include more variables for a critical and derivative analysis to examine the value of tools and how they can be used for biomimetics in Practice. The variables were chosen in line with the work of $\mathrm{Fu}$ et al. ${ }^{1}$ and Fayemi et al., ${ }^{26,29}$ but were extended with further descriptive variables. Fu et al. ${ }^{1}$ categorised their evaluation descriptively (from 'well addressed' to 'opportunity to address'); in the study presented here, the variables were extended with nominal or ordinal categories (Table 1; see also Section 2.3).

The classification of each tool was done based on the literature or other available resources - for example, websites or handbooks. Therefore, it describes an extract from published data. The classification was done by the first author, and it was verified by the second author. Both researchers agreed on the classification. A subset of tools $(n=6)$ was classified only by the first author as these tools were not commonly accessible owing to 
Table 1. Variables used for the qualitative classification of tools together with their respective categories

\begin{tabular}{ll} 
Variable & \multicolumn{1}{c}{ Category option } \\
v1: class & Abstraction, application, analysis, transfer \\
v2: type & DSC, taxonomy, thesaurus, ontology, \\
& algorithm, method \\
v3: step of the & Step 1 to step 8 \\
process & \\
v4: approach & Solution-based, problem-driven, both \\
v5: accessibility & Open-source, limited, commercial \\
v6: availability & Online, software, print \\
v7: field of & Biology, technology, both \\
knowledge & \\
v8: dimension & Stand-alone, needs previous step, facilitates \\
& following step, needs previous step and \\
& facilitates following step \\
v9: sustainability & Yes, no \\
v10: proof of & Yes, no \\
concept &
\end{tabular}

DSC, database/static list/catalogue

language-related issues. The BioM Innovation database ${ }^{3}$ was used to gather data on the usage of different tools in practice.

The limitations of this classification are, first, some tools were classified only by the first author. It was decided to include these tools so that the overview is as extensive as possible. The verified classification of 37 tools led to a clear understanding and description of the variables and their categories. Therefore, it is to be expected that the classifications of the six singly classified tools are comparable to the rest. More critical variables in terms of subjective interpretation were excluded and will be used in further studies which shall involve feedback from the developers of tools themselves. Furthermore, the development of a model of classifying and analysing tools semi-quantitatively is in progress. Most of the tools require deeper understanding and/or training. In order to describe the value of these tools, their use could be examined in workshops, as, for example, described by Glier et $a l .{ }^{30}$ which is an ongoing research. The presented results build the foundation for these analyses.

\subsection{Description of variables}

Ten variables were defined for a qualitative classification. They serve to describe the characteristics of the tools, what type of tool they are, which step of the process they facilitate, how they are accessed, whether they contribute to the field of knowledge in biology or technology, whether they can be used as stand-alone or depend on other steps, whether they were used in case studies and whether they are developed to address sustainability issues.

\subsection{1 v1: class}

Referring to Fayemi et al., ${ }^{26,29}$ tools were classified accordingly to the definition of biomimetics ${ }^{10}$ into the classes of analysis tools, abstraction tools, application tools and transfer tools. This classification is in line with the process description, defining eight steps
- step 1: problem analysis (analysis)

- step 2: abstraction of the technical problem (abstraction)

- step 3: transposition to biology (transfer)

- step 4: identification of potential biological models (application)

- step 5: selection of biological model(s) of interest (analysis)

- step 6: abstraction of biological strategies (abstraction)

- step 7: transposition to technology (transfer)

- step 8: implementation and test of the concept in the initial context (application).

\subsection{2 v2: type}

According to the earlier mentioned definition of a tool, existing tools were classified as something used in performing or supporting the process of biomimetics. This something was differentiated as database/static list/catalogue (DSC), taxonomy, thesaurus, ontology, algorithm or method. These terms are defined as follows.

A DSC is a collection of biological organisms, biological characteristics, biological construction principles, biological functions or the like. This list changes or evolves only if updated.

A taxonomy is an orderly scientific classification categorising certain principles.

Thesauri aim at facilitating communication. They function as a type of dictionary, translating biological terms into their technological equivalents and/or vice versa.

Ontologies in the present context aim to categorise biological principles and abstract the diverse phenomena of biology into descriptive functions. Tools classified as ontologies in this paper encompass those which are already implemented as an ontology.

An algorithm is an automated procedure for solving a certain task in a finite number of steps. In the context of this study, tools were classified as algorithms if they describe a set of steps which help to complete a task of the biomimetic process. It is not necessary that these tools are implemented as software.

A method describes a way of doing a task during the process of biomimetics.

\subsection{3 v3: facilitated step of the process}

The problem-driven process of biomimetics is described with eight steps (see Section 2.3.1).

The steps of the process refer to the classes mentioned under v1: analysis tools (step 1 or step 5), abstraction tools (step 2 or step 6), application tools (step 4 or step 8) and transfer tools (step 3 or step 7).

The overview of the steps given for $\mathrm{v} 1$ shows that each class covers two steps of the process; therefore, v1, class, and v3, facilitated step of the process, are closely connected. As tools may exist which belong to a certain class but facilitating only one of 
the steps of the process, these two variables were distinguished. For instance, there may be application tools which facilitate the identification of potential biological models (step 4), but they do not facilitate the implementation in technology (step 8).

The distinction between v1 and v3 allows the identification of the number of tools facilitating certain steps of the process. This analysis will enable the identification of lower or higher representations of tools for certain steps and may indicate further developments of tools.

If tools facilitate more than one step, they were accounted for each step - for example, structure-function patterns ${ }^{23}$ may serve as keywords for the search of biological models (step 4) and they can assist designers to abstract biological systems (step 6).

\subsection{4 v4: approach}

In most cases, it was not specifically indicated by the developers whether the tools were developed for the solution-based ${ }^{7}$ or problem-driven ${ }^{5,31}$ approach of biomimetics. The tools were therefore classified according to their potential usage for one or both of the approaches. As several steps of both approaches and their underlying tasks are similar - for example, the communication across interdisciplinary boundaries - tools facilitating these steps were classified as being for both approaches. A tool which is classified as for the solution-based approach only can be used, for example, for the idea generation of biologically inspired designs rather than for facilitation of a concrete transfer of biological strategies to generate a solution for a concrete problem, as would be necessary for the problem-driven approach. If a tool is classified as being for the problem-driven approach only, it focuses on finding biological models for a defined problem and therefore does not facilitate the solution-based approach.

\subsection{5 v5: accessibility}

To describe whether a tool is accessible, the tools were classified as (a) freely available literature and/or computational tool (opensource), (b) available but with limitations - for example, as a demo version only (limited) or (c) commercial if they can be purchased.

\subsection{6 v6: availability}

In contrast to accessibility, tools were furthermore classified according to their origin, as an online hosted, a printed or a software version.

This variable serves to give insight about the overall availability of the tools. Therefore, when a tool was described in the literature and was also online hosted, it was classified for the online hosted version as this emphasises its availability.

\subsection{7 v7: field of knowledge}

It was distinguished whether the tools and/or their usage addresses the body of knowledge in either biology, technology or both fields. If a tool is related, for example, to the field of knowledge of biology, it contributes by, for example, structuring, relating or clustering biological knowledge and therefore contributes to deeper insights in biology.

\subsection{8 v8: dimension}

For the description of the dimension of a tool, it was classified whether the tool can be used as a stand-alone tool, whether it needs a previous step or whether it facilitates the following step, in order to point out the interconnectedness of tools.

\subsection{9 v9: sustainability}

This variable was introduced in order to clarify whether a tool was specifically developed to increase the impact of biomimetics on sustainable and responsible innovation.

\subsubsection{0 v10: proof of concept}

If a tool was used for the development process of a product, as far as known from the BioM innovation database, ${ }^{3}$ it was classified positively with a proof of concept. Tools which were evaluated in case studies (theoretical or practical ones) in literature have also been classified as yes. Otherwise, they did not have a reported proof of concept so far.

\section{Results and discussion}

\subsection{Overview of existing tools}

Table 2 shows the overview of the 43 identified tools and methods which were developed to facilitate the process of biomimetics. They are presented with the year of publication or their documented development, a brief description and references to the source of publication. The overview is in chronological order of their development.

The search for tools identified some procedures - for example, BioGen ${ }^{7}$ or the concept-knowledge design theory ${ }^{79}$ - considered to be able to facilitate the process of biomimetics. These were not included as they do not particularly fulfil the definition of a biomimetic tool.

As mentioned before, the presented tools are derived from various disciplines. Therefore, the presentation of these existing tools is the first collection and overview at hand, which enables the reader to get to know this diversity of tools and to use them potentially in the future. The brief description of the tools is considered to help the reader understand the overall aim or context of the respective tool, so that the reader may decide whether to learn more about the tools with help of the references. Together with the results of the qualitative analysis of existing tools, a structured presentation, the interconnectedness of the tools and the mapping of tools to the process of biomimetics are given. These first steps of the analysis of tools are a state-of-the-art description of tools facilitating the process, and they outline the complexity and broadness of the problem-driven process of biomimetics. Furthermore, they build the foundation for future research, which will focus on the usability of tools in Practice, as elaborated in Section 3.3. 
Table 2. Full overview of identified tools which facilitate the process of biomimetics (continued on next page)

\begin{tabular}{|c|c|c|c|c|}
\hline & Name & Year & Description & References \\
\hline 1 & $\begin{array}{l}\text { The seven steps of Bionik (Die sieben } \\
\text { Denkschritte der Bionik) }\end{array}$ & 1987 & $\begin{array}{l}\text { Methodology, comparison of biological and technological } \\
\text { function, constraints and performance criteria to compare } \\
\text { solutions and to measure applicability }\end{array}$ & Zerbst $^{32}$ \\
\hline 2 & 16 patterns of nature 33 & 1995 & Classification of biological systems, general overview & $\begin{array}{l}\text { Hoagland and } \\
\text { Dodson } \\
33\end{array}$ \\
\hline 3 & $\begin{array}{l}\text { Catalogue of biological principles (Katalog } \\
\text { biologischer Konstruktionen) }\end{array}$ & 1998 & $\begin{array}{l}\text { Static list, biological principles for giving insight on biological } \\
\text { construction }\end{array}$ & $\mathrm{Hill}^{34}$ \\
\hline 4 & $\begin{array}{l}\text { Bioanalogous similarity matrix (Bioanaloge } \\
\text { Ähnlichkeitsmatrix) }\end{array}$ & 2002 & $\begin{array}{l}\text { Methodology, comparison of biological and technological } \\
\text { system to measure applicability }\end{array}$ & $\begin{array}{l}\text { Küppers and } \\
\text { Tributsch }\end{array}$ \\
\hline 5 & $\begin{array}{l}\text { The ten fundamental principles of biological } \\
\text { systems (Die zehn Grundprinzipien } \\
\text { biologischer Systeme) }\end{array}$ & 2002 & $\begin{array}{l}\text { Static list of ten characteristics of biological systems for a } \\
\text { deeper understanding of biology; enables to compare } \\
\text { biology and technology and to transpose principles to } \\
\text { technology }\end{array}$ & Nachtigall ${ }^{36}$ \\
\hline 6 & $\begin{array}{l}\text { BidLab search tool - natural language } \\
\text { analysis for biomimetic design }{ }^{37}\end{array}$ & 2004 & $\begin{array}{l}\text { Computational tool based on WordNet for searching texts } \\
\text { from the biology literature to identify biological analogies }\end{array}$ & Chiu and Shu ${ }^{37}$ \\
\hline 7 & Idea-Inspire 38,39 & 2005 & $\begin{array}{l}\text { Software for browsing a database of biological and artificial } \\
\text { systems for inspiration and problem-solving }\end{array}$ & Chakrabarti et al. ${ }^{38,39}$ \\
\hline 8 & $\begin{array}{l}\text { A systematic catalogue for biomimetic } \\
\text { design (Systematischer Katalog für } \\
\text { bionisches Gestalten) }{ }^{40}\end{array}$ & 2005 & $\begin{array}{l}\text { Catalogue of biological systems for a deeper understanding } \\
\text { of biological systems and the transfer to technology }\end{array}$ & $\begin{array}{l}\text { Nachtigall and } \\
\text { Wisser }^{40}\end{array}$ \\
\hline 9 & $\begin{array}{l}\text { Bioniquity (Biology - Technology - } \\
\text { Creativity) }\end{array}$ & 2005 & $\begin{array}{l}42 \text { abstracted principles of biological models which can be } \\
\text { used for idea generation on the meta level }\end{array}$ & $\mathrm{BMVIT}^{41}$ \\
\hline 10 & 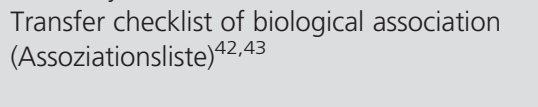 & 2006 & $\begin{array}{l}\text { Functional principles of technology which are mapped to } \\
\text { selected examples from biology; serves for association }\end{array}$ & $\begin{array}{l}\text { Gramann, }{ }^{42} \\
\text { Lindemann and } \\
\text { Gramann }^{43}\end{array}$ \\
\hline 11 & BioTriz $^{4}$ & 2006 & $\begin{array}{l}\text { Matrix for the resolution of conflicts derived from biological } \\
\text { solutions, refers to the } 40 \text { inventive principles of the theory } \\
\text { of inventive problem-solving (TRIZ) }\end{array}$ & Vincent et al. ${ }^{4}$ \\
\hline 12 & Functional modelling ${ }^{44}$ & 2008 & $\begin{array}{l}\text { Method for modelling biological systems functionally, aims } \\
\text { towards a function-based biomimetic design repository }\end{array}$ & Nagel et al. ${ }^{44}$ \\
\hline 13 & $\begin{array}{l}\text { Systematic reverse engineering of biological } \\
\text { systems }{ }^{45}\end{array}$ & 2007 & $\begin{array}{l}\text { Systematic method for reverse engineering of biological } \\
\text { systems, assists designers in identifying biological models }\end{array}$ & Wilson and Rosen ${ }^{45}$ \\
\hline 14 & Natural language analysis ${ }^{46,47}$ & 2007 & $\begin{array}{l}\text { Method for generation and ranking of biologically } \\
\text { meaningful keywords to bridge biology and engineering }\end{array}$ & Chiu and Shu ${ }^{46,47}$ \\
\hline 15 & Biologically meaningful keywords ${ }^{48,49}$ & 2008 & $\begin{array}{l}\text { Defining biologically meaningful keywords referring to the } \\
\text { terms of the functional basis }\end{array}$ & Cheong et al. ${ }^{48,49}$ \\
\hline 16 & Ontology for bioinspired design ${ }^{50}$ & 2008 & $\begin{array}{l}\text { Ontology for capturing, retrieving and reusing bioinspired } \\
\text { design solutions based on associated physical architectures, } \\
\text { behaviours, functions and strategies; aims towards internal } \\
\text { repository }\end{array}$ & Yim et al. ${ }^{50}$ \\
\hline 17 & AskNature ${ }^{19,20}$ & 2008 & $\begin{array}{l}\text { Publicly available database of biological information } \\
\text { classified by functions }\end{array}$ & $\begin{array}{l}\text { Deldin and } \\
\text { Schuknecht }{ }^{19}\end{array}$ \\
\hline 18 & Biomimicry Taxonomy ${ }^{19,51}$ & 2008 & $\begin{array}{l}\text { Static list organising biology by function and abstracted } \\
\text { functional principles }\end{array}$ & $\begin{array}{l}\text { Deldin and } \\
\text { Schuknecht }{ }^{19}\end{array}$ \\
\hline 19 & $\begin{array}{l}\text { SAPPhIRE (State change-Action-Part- } \\
\text { Phenomenon-Input-oRgan-Effect) } \\
\text { model }\end{array}$ & 2005 & Model used to represent biological or artificial systems & $\begin{array}{l}\text { Chakrabarti et al., } \\
\text { Chakrabarti }^{39}\end{array}$ \\
\hline 20 & $\begin{array}{l}\text { Categorisation of natural language } \\
\text { keywords }^{53}\end{array}$ & 2010 & $\begin{array}{l}\text { Method for categorisation of keywords to improve effectivity } \\
\text { of identifying biological phenomena }\end{array}$ & Ke et al. ${ }^{53}$ \\
\hline 21 & Functional modelling - category and scale ${ }^{54}$ & 2010 & Method for modelling biology & Nagel et al. ${ }^{54}$ \\
\hline 22 & Engineering-to-biology thesaurus ${ }^{55}$ & 2010 & $\begin{array}{l}\text { Thesaurus correlating biological terms to engineering based } \\
\text { on the functional basis lexicon }\end{array}$ & Nagel et al. ${ }^{55}$ \\
\hline 23 & Nature-inspired design principles ${ }^{56}$ & 2010 & $\begin{array}{l}\text { Natural principles based on Biomimicry 3.8's life's principles } \\
\text { and cradle-to-cradle principles }\end{array}$ & $\begin{array}{l}\text { Delft University of } \\
\text { Technology }\end{array}$ \\
\hline 24 & $\mathrm{BIOPS}^{28}$ & 2010 & $\begin{array}{l}\text { Thesaurus and dictionary for bridging technology to biology, } \\
\text { for identification of biological models; link to patent } \\
\text { database }\end{array}$ & Fraunhofer $\mathrm{IAO}^{28}$ \\
\hline 25 & $\begin{array}{l}\text { DANE (Design by Analogy to Nature } \\
\text { Engine) }{ }^{57,58}\end{array}$ & 2010 & $\begin{array}{l}\text { Computational tool, database of biological } \\
\text { Structure-Behavior-Function (SBF) models }\end{array}$ & $\begin{array}{l}\text { Vattam et al., }{ }^{57} \text { Design } \\
\text { Intelligence Lab }{ }^{58}\end{array}$ \\
\hline 26 & $\begin{array}{l}\text { Automatically populating the Biomimicry } \\
\text { Taxonomy for scalable systematic } \\
\text { biologically inspired design }\end{array}$ & 2012 & $\begin{array}{l}\text { Method for supporting structuring and selection of } \\
\text { biological designs and classifying biological analogies into } \\
\text { the Biomimicry Taxonomy }\end{array}$ & Vandevenne et al. ${ }^{59}$ \\
\hline
\end{tabular}


Table 2. Continued

\begin{tabular}{|c|c|c|c|c|}
\hline & Name & Year & Description & References \\
\hline 27 & $\begin{array}{l}\text { Automatic extraction of causally related } \\
\text { functions from natural-language text for } \\
\text { biomimetic design }\end{array}$ & 2012 & $\begin{array}{l}\text { Tool for identifying relevant linguistic patterns in biological } \\
\text { text }\end{array}$ & Cheong and Shu ${ }^{60}$ \\
\hline 28 & $\begin{array}{l}\text { A computational approach to biologically } \\
\text { inspired design }\end{array}$ & 2012 & Algorithm for biologically inspired concept generation & $\begin{array}{l}\text { Nagel and Stone, } \\
\text { Design Engineering } \\
\text { Lab }^{62}\end{array}$ \\
\hline 29 & Life's principles ${ }^{11,63}$ & 2008 & 26 fundamental principles of biology, refers to sustainability & $\begin{array}{l}\text { Baumeister et al., }{ }^{11} \\
\text { Benyus }^{63}\end{array}$ \\
\hline 30 & Biologue $e^{64,65}$ & 2013 & $\begin{array}{l}\text { Interactive online information system for collaborative semantic } \\
\text { annotation of biology articles, leading to internal repository; } \\
\text { search engine for semantically annotated biology articles }\end{array}$ & $\begin{array}{l}\text { Vattam and Goel, } \\
\text { Design } \& \text { Intelligence } \\
\text { Laboratory }^{65}\end{array}$ \\
\hline 31 & Ontology of biomimetics ${ }^{66}$ & 2014 & $\begin{array}{l}\text { Ontology of biological functions, refers to the } 40 \text { innovative } \\
\text { principles of TRIZ }\end{array}$ & Vincent $^{66}$ \\
\hline 32 & bionicinspiration.org ${ }^{67}$ & 2014 & Website offering bionic categories and case studies & bionicinspiration. org $^{67}$ \\
\hline 33 & Ontology Explorer ${ }^{68,69}$ & 2014 & $\begin{array}{l}\text { Web tool for identification of biological models and } \\
\text { exploring biomimetics database }\end{array}$ & $\begin{array}{l}\text { Kozaki et al., } \\
\text { Kozaki }\end{array}$ \\
\hline 34 & $\begin{array}{l}\text { Unified ontology for causal-function modeling } \\
\text { in biologically inspired design (UNO-BID) }\end{array}$ & 2014 & Process description, including biomimetic tools & Rosa et al. ${ }^{70}$ \\
\hline 35 & Four-Box method ${ }^{9}$ & 2014 & $\begin{array}{l}\text { Problem formulation and analogy evaluation; describes } \\
\text { function, operational environment, specifications and } \\
\text { performance criteria of systems }\end{array}$ & Helms and Goel ${ }^{9}$ \\
\hline 36 & T-chart $^{9}$ & 2014 & $\begin{array}{l}\text { Analogy evaluation, comparison of biological and } \\
\text { technological systems }\end{array}$ & Helms and Goel ${ }^{9}$ \\
\hline 37 & Bioscrabble $^{71}$ & 2014 & $\begin{array}{l}\text { Software supporting search term-based extraction of } \\
\text { biological analogies out of large text sources, supports } \\
\text { managing results }\end{array}$ & Kaiser et al. ${ }^{71}$ \\
\hline 38 & $\begin{array}{l}\text { BioP-C: the Biology Phenomenon } \\
\text { Categorizer }\end{array}$ & 2014 & $\begin{array}{l}\text { Computation game; collects computable knowledge about } \\
\text { biological phenomena and assesses their quality; } \\
\text { benchmarks are AskNature, Dane, Idea-Inspire and natural- } \\
\text { language search tools }\end{array}$ & Arlitt et al. ${ }^{72}$ \\
\hline 39 & Biotransferability framework ${ }^{73}$ & 2014 & $\begin{array}{l}\text { Combination of stochastic multicriteria acceptability analysis with } \\
\text { criteria from biologically-inspired design (BID) to evaluate the } \\
\text { utility of biological analogies and the biology-to-engineering risk }\end{array}$ & Williams et al. ${ }^{73}$ \\
\hline 40 & Structure-Function Patterns ${ }^{74}$ & 2014 & $\begin{array}{l}\text { Table of biological structure-function patterns, provides } \\
\text { keywords for searching biological databases, helps to } \\
\text { abstract biological texts, for identifying biological models, } \\
\text { useful for idea generation }\end{array}$ & $\begin{array}{l}\text { Helfman Cohen } \\
\text { et al. }{ }^{74}\end{array}$ \\
\hline 41 & Design Study Library ${ }^{75}$ & 2015 & $\begin{array}{l}\text { Web tool, searches case studies of a digital library, supports } \\
\text { analogical learning }\end{array}$ & Goel et al. ${ }^{75}$ \\
\hline 42 & Nature-inspired solutions ${ }^{76,77}$ & 2015 & $\begin{array}{l}\text { Design principles and methodology, biological principles for } \\
\text { sustainable innovation }\end{array}$ & Karim Network ${ }^{76}$ \\
\hline 43 & Resilient Design cards ${ }^{78}$ & 2015 & $\begin{array}{l}\text { Based on design principles found in nature, methodology for } \\
\text { sustainable innovation }\end{array}$ & ResilieNtWeb ${ }^{78}$ \\
\hline
\end{tabular}

\subsection{Qualitative analysis}

The full classification of six tools as an example for each type of tool is shown in Table 3. The charts and graphs in this section summarise the classification of the existing tools. In addition, cross-connections between variables are presented.

\subsubsection{Development of tools: 1987-2015 $(n=43)$}

Figure 2 shows that over the past decades, tools have been consistently developed, with an increase in the number of tools in 2014. The graph does not give insight into whether the developed tools were an update or improvement of an existing tool or a new development.

It is assumed that recent tools consist of newer knowledge on biomimetics. However, as scientific literature on biomimetics reached a peak with nearly 3000 publications per year in $2013,{ }^{2}$ it remains an open question whether this knowledge has influenced the development of tools facilitating the process of biomimetics. There do exist methods of a structured way of extracting principles from, for example, the body of biological literature for several purposes, ${ }^{74,80}$ and these approaches could be adapted for this endeavour.

In order to identify more tools in the future, it would be helpful to have commonly used keywords and a clear naming of tools.

\subsubsection{Classes of tools $(n=43)$}

If tools facilitate various steps of the process, they were counted for each class respectively. Most of the analysed tools serve as transfer $(33 \%)$ and application (37\%) tools, while in comparison, analysis $(12 \%)$ and abstraction $(18 \%)$ tools are less represented. 
Table 3. The full classification of tools developed to facilitate the process of biomimetics

\begin{tabular}{|c|c|c|c|c|c|c|}
\hline \multirow[b]{2}{*}{ Variable } & \multicolumn{6}{|c|}{ Category option } \\
\hline & AskNature ${ }^{19,20}$ & $\begin{array}{l}\text { Biomimicry } \\
\text { Taxonomy }{ }^{51}\end{array}$ & Biops $^{28}$ & $\begin{array}{c}\text { Ontology } \\
\text { Explorer } 68,69\end{array}$ & $\begin{array}{l}\text { Automatically populating } \\
\text { the Biomimicry } \\
\text { Taxonomy for scalable } \\
\text { systematic biologically } \\
\text { inspired design }\end{array}$ & $\begin{array}{l}\text { Functional } \\
\text { modelling }^{44}\end{array}$ \\
\hline v1: class & Application & Transfer & $\begin{array}{l}\text { Transfer, } \\
\text { application }\end{array}$ & Application & Application & Abstraction \\
\hline v2: type & DSC & Taxonomy & Thesaurus & Ontology & Algorithm & Method \\
\hline $\begin{array}{l}\text { v3: step of the } \\
\text { process }\end{array}$ & Step 4 & Step 3 & Step 3 and step 4 & Step 4 & Step 4 & Step 6 \\
\hline v4: approach & Both & Problem-driven & Problem-driven & $\begin{array}{l}\text { Problem- } \\
\text { driven }\end{array}$ & Both & Both \\
\hline v5: accessibility & Open-source & Open-source & Limited & Open-source & Limited & Open-source \\
\hline v6: availability & Online & Print & Online & Online & Print & Print \\
\hline $\begin{array}{l}\text { v7: field of } \\
\text { knowledge }\end{array}$ & Both & Technology & Both & Technology & Both & Biology \\
\hline v8: dimension & $\begin{array}{l}\text { Needs previous } \\
\text { step and } \\
\text { facilitates } \\
\text { following step }\end{array}$ & $\begin{array}{l}\text { Needs previous } \\
\text { step and } \\
\text { facilitates } \\
\text { following step }\end{array}$ & $\begin{array}{l}\text { Needs previous } \\
\text { step and } \\
\text { facilitates } \\
\text { following step }\end{array}$ & Stand-alone & $\begin{array}{l}\text { Needs previous } \\
\text { step and facilitates } \\
\text { following step }\end{array}$ & $\begin{array}{l}\text { Needs previous } \\
\text { step and } \\
\text { facilitates } \\
\text { following step }\end{array}$ \\
\hline v9: sustainability & Yes & No & No & No & No & No \\
\hline $\begin{array}{l}\text { v10: proof of } \\
\text { concept }\end{array}$ & Yes & Yes & Yes & Yes & Yes & Yes \\
\hline
\end{tabular}

The table shows the respective classification for one tool of each type

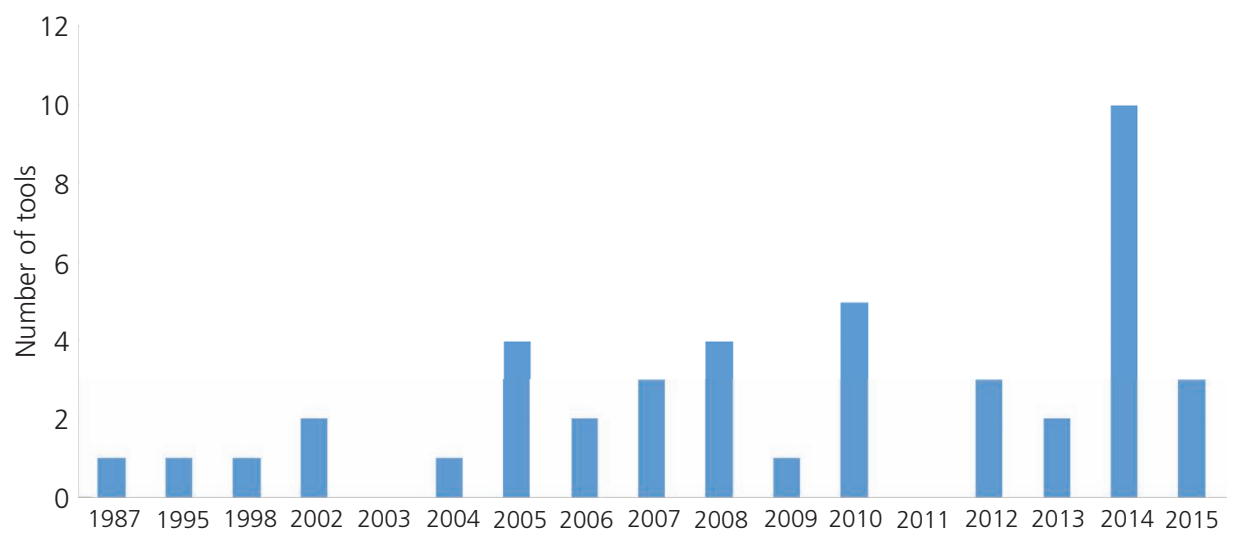

Figure 2. Number of tools published per year (1987-2015)

All four classes cover two steps of the process and focus on tasks in the field of technology or biology. In future research, the following shall be analysed: how existing tools are used at present, where challenges remain, which users' needs exist and whether the usage of tools fosters the success of the respective steps.

\subsubsection{Type of tools $(n=43)$}

Thirty-seven per cent of the analysed tools are DSC. According to their basic definition, they change only if updated and offer a prescribed amount of knowledge. Considering the increase of scientific literature, ${ }^{2}$ existing databases or catalogues have the potential to evolve and grow over time. However, this is a very time-consuming task, so other tools apart from databases were developed to screen scientific literature and update automatically (e.g. Kaiser et al. ${ }^{71}$ Vandevenne et al. ${ }^{81}$ ).

Only one taxonomy was identified, which is the Biomimicry Taxonomy. ${ }^{19,51}$ This taxonomy categorises biology in terms of function and helps to address biology.

Two thesauri were identified. ${ }^{28,55}$ As the communication across interdisciplinary boundaries is one of the described challenges, ${ }^{6}$ these tools were designed to overcome this challenge and to bridge the gap between disciplines (see Figure 1). 
In this study, three ontologies were identified. The ontologies focus on describing nature with abstracted functional principles $^{51,66}$ and serve different objectives; one of these is the Ontology Explorer. ${ }^{6,69}$

Algorithms (30\%) and methods (19\%) both address a systematic way of performing a certain step of the process.

Some tools and methods are developed with cross-links to other tools (e.g. Vandevenne et al., ${ }^{59}$ Kozaki and Mizoguchi ${ }^{68}$ ). This aspect points out the potential for co-creating tools. Further research is needed to elaborate on this idea.

\subsubsection{Application to biomimetic approaches $(n=43)$}

All classified tools facilitate the tasks of the problem-driven approach, and in addition, more than half of them can be used for the problem-driven approach only. The other half can be used for overlapping tasks of both approaches. This indicates that there are several tasks in both approaches which are similar and can be facilitated by existing tools. Interestingly, $33 \%$ of the BioM case studies were based on the problem-driven approach, which the authors consider to be of more relevance to industry needs. The communication of existing tools might foster their usage in Practice.

No tools were identified which facilitate the solution-based approach only. Such tools could focus on the systematic knowledge transfer from biology to technology, and they could help to access and structure scientific biological knowledge about certain models. Furthermore, such a strategic approach could strengthen the role of biologists and their expertise in biomimetics, which is crucial for the process. ${ }^{82}$ As shown with the BioM database, ${ }^{3} 55 \%$ (41 out of 75 ) of the analysed case studies were derived from the solution-based approach, which means mostly serendipity. Tools focusing on the solution-based approach could shift serendipity to a more deliberate way of accessing biology.

Existing ontologies or catalogues of biological principles already contribute to this aspect; further development could focus on presenting clusters of multifold developments of nature, combined with underlying deep patterns, or presenting individual biological role models with their specific characteristics and phenomena from the perspective of a solution-based approach. This has already been proposed, ${ }^{83}$ and several works have focused on various aspects (e.g. Helfman et al. ${ }^{74}$ Cheong et al.,${ }^{84}$ Hoeller et $a l .,{ }^{85}$ Yen and Weissburg ${ }^{86}$ ). As mentioned before, a co-creation could contribute to this task - for example, the functional modelling of biological systems could be included.

\subsubsection{Facilitating steps of the problem-driven approach of biomimetics $(n=43)$}

Figure 3 shows the mapping of existing tools to the steps of the problem-driven approach of biomimetics and is closely connected to the classes of tools. Tools which facilitate several steps were counted for each of the steps.

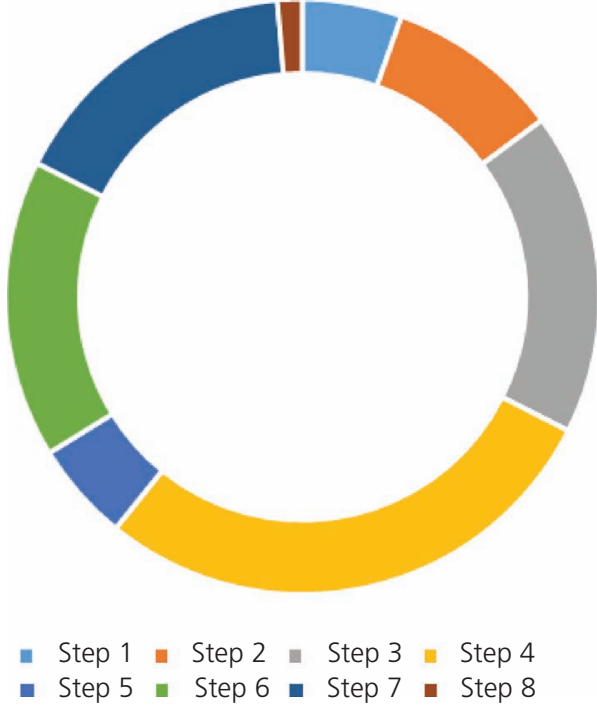

Figure 3. Steps of the problem-driven approach of biomimetics facilitated by classified tools

\subsubsection{ANALYSIS STEPS}

Step 1 of the problem-driven approach of biomimetics is facilitated by four tools. This step serves in analysing the problem. One of the main challenges in biomimetics is defining the problem well enough (e.g. Yen et al. ${ }^{6}$ ) before engaging in the process of biomimetics. One could assume that the usage of tools developed particularly for this step could help to overcome this challenge. It is not necessary that such tools be derived from the community of biomimetics; they could come from other disciplines - for example, the TRIZ community. Step 5, which serves the analysis of biological models and their selection, is facilitated by four tools. Step 5 is a crucial step and further development could help to increase the implementation of biomimetics by bridging the second gap of the process (see Figure 1).

\subsubsection{ABSTRACTION STEPS}

Step 2 and step 6 serve the abstraction of the technical problem or the biological strategy, respectively. Both steps are facilitated by a small subset of tools (step 2: $n=7$; step 6: $n=12$ ). It remains an open research question whether these two steps may be facilitated by tools or whether they are mostly dependent on the expertise from individuals of both fields. The authors consider the abstraction a learning process and a new way of thinking about, for example, biological systems, as the abstraction reduces principles of living systems, for example, to their underlying physical-chemical properties in order to make these principles applicable in non-living technical systems. Abstracting biological principles is one of the two most challenging tasks during biomimetics, next to the identification of biological systems. ${ }^{74}$ Tools facilitating this step in particular can help to overcome this challenge.

\subsubsection{TRANSFER STEPS}

Twenty-five tools exist which facilitate step 3 and step 7, the transposition from technology to biology and vice versa. These steps 
are important for bridging both fields of knowledge. Further practical analysis of these tools could measure their impact and their usage.

\subsubsection{APPLICATION STEPS}

Step 4, identification of biological systems, is facilitated by the highest number of tools $(n=21)$. The identification of biological systems seems to have been one of the most prominent steps to work on, as it is the second of the two most challenging tasks. ${ }^{74}$ Therefore, many tools have been developed to facilitate this step. As most of the biological species on this planet are still to be discovered and described, the identification of biological models out of the scientific literature remains an ongoing process. This fact also strengthens the necessary role of biologists in the field of biomimetics. $^{82}$

Step 8 , implementation and test in the initial context, is facilitated by only one tool and is closely connected to the problem space and the technological application. Therefore, tools from other disciplines may be included to facilitate the steps, not necessarily deriving from biomimetics in particular.

Figure 4 presents the number of tools, distinguished by their type, which facilitate the different steps of the process. It is shown that DSCs and algorithms cover steps 2-7 of the process, while DSCs can also be used for the analysis (step 1) and implementation step (step 8). So far, methods are mainly used not only for the abstraction steps of the process, but also for the selection of a biological model (step 5).

\subsubsection{Field of knowledge $(n=43)$}

The knowledge in both biology and technology usually increase during the process of biomimetics as they are connected in a heuristic spiral. ${ }^{87}$ At present, around one fifth of the tools contribute to the knowledge about biological systems, while $37 \%$ of the tools contribute in particular to the area of technology. $42 \%$ contribute to both fields. Further research on the underlying principles of knowledge transfer in biomimetics could contribute to a better understanding of needs and how to overcome them. This aspect could lead to a deeper understanding of the process in Practice and may lead to an improvement of the state of the art.

\subsubsection{Availability and accessibility $(n=43)$}

Most of the tools $(65 \%)$ are described only in the scientific literature, and the information about their objectives and potential is available through literature. It remains an open research question whether this fact limits the usage of existing tools, particularly in the field of industrial application. A further theoretic analysis of the existing tools, based on the data presented in this paper, could therefore help to bridge communication gaps and to open the access to the high potential of the existence of tools. Combined with practical analyses of tools, a contribution to the future evolution of biomimetics towards a broader concept could be achieved.

More than $48 \%$ of the tools are available as open-source, while $46 \%$ offer limited access. The developers of the AskNature database $^{20}$ stated that the provision of a free and publicly available tool is important. ${ }^{19}$

If the tools in the future are more often available freely, the necessary interdisciplinarity of the biomimetic process could be enhanced as beneficiaries from various disciplines have access to tools and may share resources. Such a trend could lead to the improvement of the process, as it would open the process towards the involvement of more people with diverse expertise.

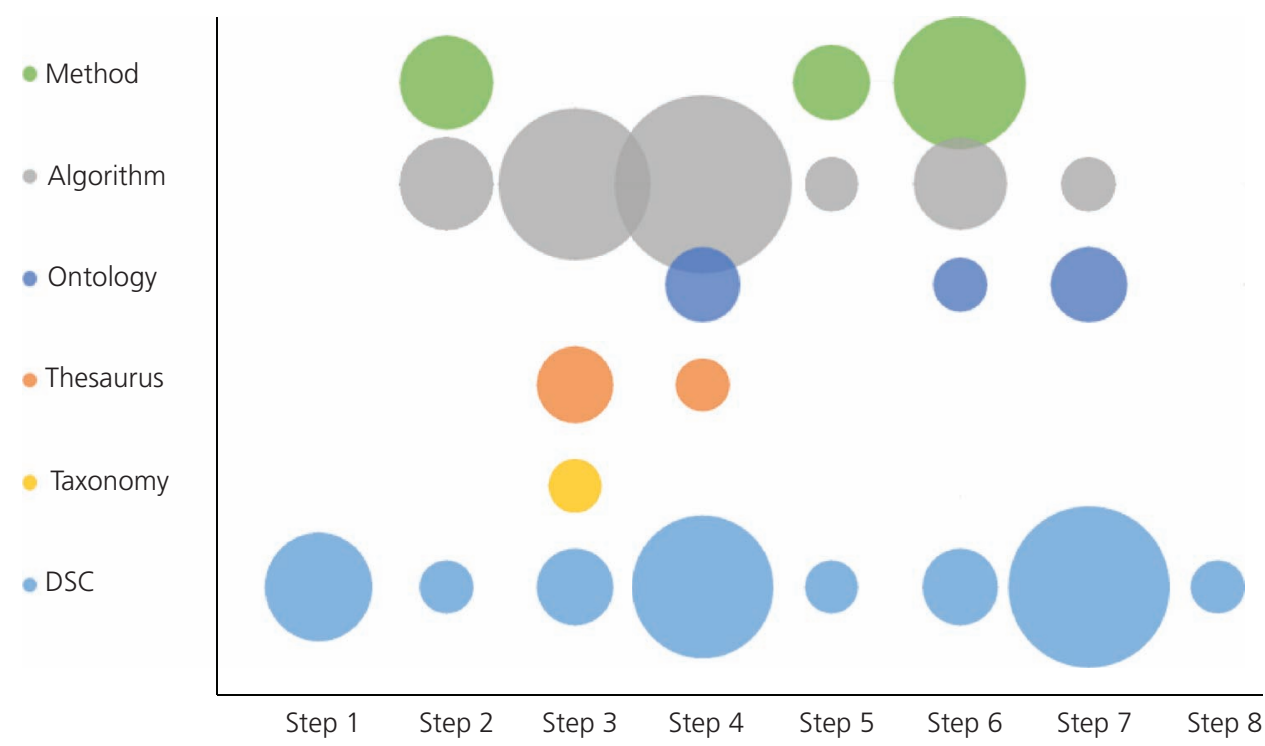

Figure 4. Type of tools facilitating the eight steps of the problem-driven approach of biomimetics. The size of the bubbles indicates the number of tools 


\subsubsection{Proof of concept $(n=43)$}

Seventy-seven per cent of the classified tools were tested in theoretical or practical case studies, as described in the respective literature. Theoretically, the tested tools have shown their potential for usage in the process of biomimetics, but as mentioned before, they do not seem to be used widely. ${ }^{3}$ Only the AskNature website ${ }^{20}$ was mentioned in interviews with the developers and then mostly as a means of motivation to explore their own process. ${ }^{3}$ Further research on the impact, successes and challenges of single tools in Practice could contribute to the improvement of the state of the art. This research could be done by workshops or interviews with industrial partners.

\subsubsection{Dimension $(n=43)$}

It has been reported that the process of biomimetics is not linear, but rather consists of feedback loops and iterations (e.g. Badarnah and Kadri, ${ }^{7}$ ISO, ${ }^{10}$ Baumeister et $\left.a l .{ }^{11}\right)$. This statement is strengthened by the classification, as $60 \%$ of the tools facilitate next steps, need previous steps or do both. Forty per cent of the tools can be considered to be stand-alone. It could be tested whether the stand-alone capacity could foster the usage and the impact of respective tools. Future analyses shall be used to clarify the impact of the interconnectedness of tools on the process. It could also be analysed whether the classified tools were developed individually, so that the state of the art could be improved if interconnected steps and their tools are taken into account during the improvement of existing or the development of new tools.

Further studies will focus on the connectedness of tools and their potential interdependencies. Practical analyses, such as workshops, shall follow, be it on teaching students or for training of beneficiaries from the business sector. Further research needs to be done in order to identify different needs and gaps, in order to check the appropriateness of tools for different audiences (e.g. Fu et al. ${ }^{1}$ ).

\subsubsection{Sustainability $(n=43)$}

Five of the 43 analysed tools were developed with the objective of addressing the environmental sustainability of biomimetic concepts in particular. The contribution of biomimetics to more sustainable innovation is discussed in various aspects (e.g. ISO, ${ }^{10}$ Reap and Bras, ${ }^{80}$ De Pauw et al. ${ }^{88}$ Reap et al. ${ }^{89} \mathrm{Mead}^{90}$ ), and in this classification, no detailed analysis was performed. It was only distinguished whether the tool itself contains aspects which address particularly the environmental sustainability of the target concept. Still, research on how to assess the impact of biomimetic concepts on environmental sustainability is ongoing (e.g. Antony et $\left.a l^{91}\right)$. Once more tools are identified which address sustainability in particular, further research could evaluate how to include the potential of biomimetics for sustainability in the whole process and at certain steps.

\subsection{Use of tools in Practice and outlook}

As shown in Figure 5, tools can be used for the process of biomimetics. Most of the tools were developed individually and independently, whereas with the presented work, the authors aimed to point out that these tools can be used together in practice (see also Fayemi et $a l .{ }^{26}$ ). Variable v10, proof of concept, shows that more than three out of four of the presented tools have been analysed in theoretical or practical case studies to show their value. If one wants to implement biomimetics in Practice and is facing several challenges (as shown in Figure 1), the respective tools can help to overcome those challenges. Figure 5 shows an example of how to make use of the presented tools in practice by using them at certain steps of the process.

This general example gives a generic overview about how tools can be mapped to the process; it does not specify or analyse the problem which shall be solved through a bioinspired solution. Further analysis of the tools can help to assess the value of tools in Practice, which can be done, for example, through training of users and assessing their success with certain tools. The results of this research have led to a framework of the usage of tools. ${ }^{92}$ Furthermore, ongoing research will help to assess the value of tools for certain problems, contexts and desired aims of the process - for instance, the aim for a functional optimisation of products or for a more sustainable product development. The following research questions will be addressed in the future.

- How can the suitability for biomimetics for certain problems be assessed?

- Which tools can be used to perform the defined tasks of the process of biomimetics?

- How are the tools interconnected?

- How can users be helped to choose an appropriate tool?

\section{Conclusion}

The presented study has given an overview of existing tools which facilitate the process of biomimetics and its problem-driven approach

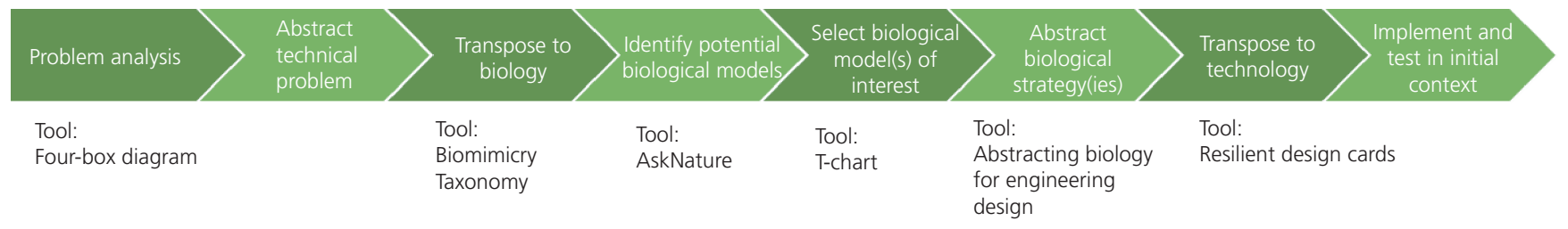

Figure 5. Potential use of tools in practice. Tools can be chosen for certain steps of the process of biomimetics (see Fayemi et al. ${ }^{26,29}$ ) to facilitate the underlying tasks 
in particular. This overview has been lacking so far; this study is the first presentation of 43 tools with their connections to the process, and it presents the diversity of biomimetics in terms of research communities and their respective areas of interest. Not only do results from scientific biomimetics contribute to the process, but so do results from other linked disciplines, such design, engineering, product development, creativity or cognition. This diversity is the product of the complexity of biomimetics, which the authors consider to be challenging, particularly for non-experts, but with significant potential for closer collaboration of research areas and stronger interdisciplinary and, more importantly, transdisciplinary co-operation and communication, as well as a fostered knowledge transfer between the academia and industry. Therefore, the presented overview forms the foundation for a broader usage of the tools as potential users find a summary of the scattered tools. In addition, based on this overview and the first analysis which shows the interconnectedness of tools, further research can be performed - for example, through workshops and interviews which help to identify the value of certain tools. This is ongoing research. Furthermore, it was shown that the analysis of tools may lead to improvements of the state of the art, which can be achieved only collaboratively.

The presented work is in progress and is the foundation for a future theoretical statistical analysis. Such an analysis can also encompass analyses of target audiences and their needs, in order to foster the implementation and usage of biomimetics and its tools in education and application. Further theoretical analysis of existing tools is planned in order to identify the principal characteristics of the tools and the underlying patterns of their objectives, successes and drawbacks. Future work is also considered to take into account feedback from the developers and from beneficiaries. This analysis is supposed to draw conclusions for the current process of biomimetics and for the development of new tools. It will be interesting to see how existing and new tools will address current challenges and how they will be designed in order to support different groups of users.

With an increase of research and development in biomimetics in various disciplines, the authors look forward to the option that the well-known potential of biomimetics to become a paradigm in several technological disciplines ${ }^{2}$ might be expanded to other fields of research and application. This could lead to an increase in nature-inspired solutions to address the most challenging problems of the present time.

\section{REFERENCES}

1. Fu K, Moreno D, Yang M and Wood KL (2014) Bio-inspired design: an overview investigating open questions from the broader field of design-by-analogy. Journal of Mechanical Design 136(11): 111102.

2. Lepora NF, Verschure P and Prescott TJ (2013) The state of the art in biomimetics. Bioinspiration \& Biomimetics 8(1): 013001.

3. Jacobs SR, Nichol EC and Helms ME (2014) 'Where are we now and where are we going?' the BioM innovation database. Journal of Mechanical Design 136(11): 111101.

4. Vincent JFV, Bogatyreva OA, Bogatyrev NR, Bowyer A and Pahl AK (2006) Biomimetics: its practice and theory. Journal of the Royal Society Interface 3(9): 471-482.
5. Helms M, Vattam SS and Goel AK (2009) Biologically inspired design: process and products. Design Studies 30(5): 606-622.

6. Yen J, Helms M, Goel A, Tovey C and Weissburg M (2014) Adaptive evolution of teaching practices in biologically inspired design. In Biologically Inspired Design (Goel AK, McAdams DA and Stone RB (eds)). Springer, London, UK, pp. 153-199.

7. Badarnah L and Kadri U (2015) A methodology for the generation of biomimetic design concepts. Architectural Science Review 58(2): $120-133$.

8. Nagel JKS and Stone RB (2012) A computational approach to biologically inspired design. Artificial Intelligence for Engineering Design, Analysis and Manufacturing 26(2): 161-176.

9. Helms M and Goel AK (2014) The Four-Box method: problem formulation and analogy evaluation in biologically inspired design. Journal of Mechanical Design 136(11): 111106.

10. ISO (International Organization for Standardization) (2015) ISO 18458:2015: Biomimetics - terminology, concepts and methodology. Beuth Verlag, Berlin, Germany.

11. Baumeister D, Tocke R, Dwyer J and Ritter S (2013) Biomimicry Resource Handbook: a Seed Bank of Best Practices. Biomimicry 3.8, Missoula, MT, USA.

12. Arzt E (2006) Biological and artificial attachment devices: lessons for materials scientists from flies and geckos. Materials Science and Engineering: C 26(8): 1245-1250.

13. Meyers MA, McKittrick J and Chen PY (2013) Structural biological materials: critical mechanics-materials connections. Science 339(6121): 773-779.

14. Naleway SE, Porter MM, McKittrick J and Meyers MA (2015) Structural design elements in biological materials: application to bioinspiration. Advanced Materials 27(37): 5455-5476.

15. Wegst UGK, Bai H, Saiz E, Tomsia AP and Ritchie RO (2014) Bioinspired structural materials. Nature Materials 14: 23-36.

16. Barthelat $F$ (2007) Biomimetics for next generation materials. Philosophical Transactions of the Royal Society A: Mathematical, Physical and Engineering Sciences 365(1861): 2907-2919.

17. Barthelat $F$ (2015) Architectured materials in engineering and biology: fabrication, structure, mechanics and performance. International Materials Reviews 60(8): 413-430.

18. Chen PY, McKittrick J and Meyers MA (2012) Biological materials: functional adaptations and bioinspired designs. Progress in Materials Science 57(8): 1492-1704.

19. Deldin JM and Schuknecht M (2014) The AskNature database: enabling solutions in biomimetic design. In Biologically Inspired Design (Goel AK, McAdams DA and Stone RB (eds)). Springer, London, UK, pp. 17-27.

20. Biomimicry Institute (2016) http://www.asknature.org/ (accessed 27/03/2016).

21. von Gleich A, Pade C, Petschow U and Pissarskoi E (2010) Potentials and Trends in Biomimetics. Springer, Heidelberg, Germany.

22. Stone RB, Goel AK and McAdams DA (2014) Charting a course for computer-aided bio-inspired design. In Biologically Inspired Design (Goel AK, McAdams DA and Stone RB (eds)). Springer, London, UK, pp. 1-16.

23. Glier MW, Tsenn J, Linsey JS and McAdams DA (2011) Methods for supporting bioinspired design. In Proceedings of the ASME 2011 International Mechanical Engineering Congress and Exposition, November 11-17, Denver, Colorado, USA. American Society of Mechanical Engineers, New York, NY, USA, pp. 737-744.

24. Goel AK, McAdams DA and Stone RB (2014) Biologically Inspired Design: Computational Methods and Tools. Springer, London, UK

25. Nagel JKS and Stone RB (2011) A systematic approach to biologically-inspired engineering design. In Proceedings of the ASME 2011 International Design Engineering Technical Conferences and Computers and Information in Engineering Conference. American Society of Mechanical Engineers, New York, NY, USA, pp. 153-164. 
26. Fayemi PE, Maranzana N, Aoussat A and Bersano G (2015) Assessment of the biomimetic toolset - design spiral methodology analysis. In ICoRD'15 - Research into Design across Boundaries (Chakrabarti A (ed.)). Springer, New Delhi, India, vol. 2, pp. 27-38.

27. Dinar M, Shah JJ, Cagan J et al. (2015) Empirical studies of designer thinking: past, present, and future. Journal of Mechanical Design 137(2): 021101.

28. Fraunhofer IAO (2016). http://www.nature4innovation.com (accessed 23/12/2016).

29. Fayemi PE, Maranzana N, Aoussat A and Bersano G (2014) Bioinspired design characterisation and its links with problem solving tools. In Proceedings of the International Design Conference DESIGN (Marjanović D, Štorga M, Pavković N and Bojčetić N (eds)). The Design Society, Glasgow, UK, pp. 173-182.

30. Glier MW, Tsenn J, McAdams DA and Linsey JS (2014) Evaluating methods for bioinspired concept generation. In Design Computing and Cognition '12 (Gero JS (ed.)). Springer, Dordrecht, the Netherlands, pp. 41-57.

31. Vattam S, Helms ME and Goel AK (2007) Biologically-inspired Innovation in Engineering Design: a Cognitive Study. Graphics, Visualization and Usability Center, Georgia Institute of Technology, Atlanta, GA, USA, GIT-GVU-07-07.

32. Zerbst EW (1987) Bionik: Biologische Funktionsprinzipien und ihre technischen Anwendungen. Teubner, Stuttgart, Germany (in German).

33. Hoagland MB and Dodson B (1995) The Way Life Works. Times Books, New York, NY, USA.

34. Hill B (1998) Erfinden mit der Natur: Funktionen und Strukturen biologischer Konstruktionen als Innovationspotentiale für die Technik. Shaker, Aachen, Germany (in German).

35. Küppers U and Tributsch H (2002) Verpacktes Leben-verpackte Technik Bionik der Verpackung. Wiley-VCH, Weinheim, Germany (in German).

36. Nachtigall W (2002) Bionik: Grundlagen und Beispiele für Ingenieure und Naturwissenschaftler. Springer, Berlin, Germany (in German).

37. Chiu I and Shu LH (2004) Natural language analysis for biomimetic design. Proceedings of ASME 2004 International Design Engineering Technical Conferences and Computers and Information in Engineering Conference. American Society of Mechanical Engineers, New York, NY, USA, vol. 2004, pp. 99-107.

38. Chakrabarti A, Sarkar P, Leelavathamma B and Nataraju BS (2005) A behavioural model for representing biological and artificial systems for inspiring novel designs. DS 35: Proceedings ICED 05, the 15th International Conference on Engineering Design, Melbourne, Australia, pp. 184-185.

39. Chakrabarti A, Sarkar P, Leelavathamma B and Nataraju BS (2005) A functional representation for aiding biomimetic and artificial inspiration of new ideas. AI EDAM 19(2): 113-132.

40. Nachtigall W and Wisser A (2005) Biologisches Design systematischer Katalog für bionisches Gestalten. Springer, Berlin, Germany (in German).

41. BMVIT (Bundesministerium für Verkehr Innovation und Technologie) (2010) Bionik - Innovation und Qualifikation. BMVIT, Wien, Austria (in German).

42. Gramann J (2004) Problemmodelle und Bionik als Methode. Dr. Hut, Munich, Germany (in German).

43. Lindemann U and Gramann J (2004) Engineering design using biological principles. In DS 32: Proceedings of DESIGN 2004, the 8th International Design Conference, Dubrovnik, Croatia, pp. 355-360.

44. Nagel RL, Midha PA, Tinsley A et al. (2008) Exploring the use of functional models in biomimetic conceptual design. Journal of Mechanical Design 130(12): 121102.

45. Wilson JO and Rosen D (2007) Systematic reverse engineering of biological systems. In Proceedings of ASME 2007 International Design Engineering Technical Conferences and Computers and Information in Engineering Conference, September 4-7, Las Vegas, Nevada, USA. American Society of Mechanical Engineers, New York, NY, USA, pp. 69-78.
46. Chiu I and Shu LH (2007) Using language as related stimuli for concept generation. AI EDAM 21(2): 103-121.

47. Chiu I and Shu LH (2007) Biomimetic design through natural language analysis to facilitate cross-domain information retrieval. $A I$ EDAM 21(1): 45-59.

48. Cheong H, Chiu I, Shu LH, Stone RB and McAdams DA (2011) Biologically meaningful keywords for functional terms of the functional basis. Journal of Mechanical Design 133(2): 021007.

49. Cheong H, Shu LH, Stone RB and McAdams DA (2008) Translating terms of the functional basis into biologically meaningful keywords. In Proceedings of the ASME 2008 International Design Engineering Technical Conferences and Computers and Information in Engineering Conference, August 3-6, Brooklyn, New York, USA. American Society of Mechanical Engineers, New York, NY, USA, pp. 137-148.

50. Yim S, Wilson JO and Rosen DW (2008) Development of an ontology for bio-inspired design using description logics. In Proceedings of the International Conference on Product Lifecycle Management (Bouras A, Gurumoorthy B, McMahon C and Ramani K (eds)). Inderscience Enterprises Ltd, Geneva, Switzerland, pp. 319-328.

51. Biomimicry Institute (2016) Biomimicry Taxonomy. Biomimicry Institute, Missoula, MT, USA. See http://biomimicry.org/wp-content/ uploads/2016/02/Biomimicry Taxonomy TBI.pdf (accessed 14/03/2016).

52. Chakrabarti A (2009) Sapphire - an approach to analysis and synthesis. DS 58-2: Proceedings of ICED 09, the 17th International Conference on Engineering Design, Vol. 2, Design Theory and Research Methodology, Palo Alto, CA, USA, pp. 417-428.

53. Ke J, Chiu I, Wallace JS and Shu LH (2010) Supporting biomimetic design by embedding metadata in natural-language corpora. In Proceedings of ASME 2010 International Design Engineering Technical Conferences and Computers and Information in Engineering Conference, August 15-18, Montreal, Quebec, Canada. American Society of Mechanical Engineers, New York, NY, USA, pp. 167-174.

54. Nagel JKS, Nagel RL, Stone RB and McAdams DA (2010) Functionbased, biologically inspired concept generation. Artificial Intelligence for Engineering Design, Analysis and Manufacturing 24(4): 521-535.

55. Nagel JKS, Stone RB and McAdams DA (2010) An engineering-tobiology thesaurus for engineering design. Proceedings of ASME 2010 International Design Engineering Technical Conferences and Computers and Information in Engineering Conference, August 15-18, Montreal, Quebec, Canada. American Society of Mechanical Engineers, New York, NY, USA, pp. 117-128.

56. Delft University of Technology (2016) Nature Inspired Design. Delft University of Technology, Delft, the Netherlands. See http://www. natureinspireddesign.nl/ (accessed 27/03/2016).

57. Vattam S, Wiltgen B, Helms M, Goel AK and Yen J (2011) DANE: fostering creativity in and through biologically inspired design. In Design Creativity 2010 (Taura T and Nagai Y (eds)). Springer, London, UK, pp. 115-122.

58. Design Intelligence Lab (2016) DANE: Design Analogy to Nature Engine. Design Intelligence Lab, Atlanta, Georgia Institute of Technology, Atlanta, GA, USA. See http://dilab.cc.gatech.edu/dane/ (accessed 27/03/2016).

59. Vandevenne D, Verhaegen PA, Dewulf S and Duflou JR (2012) Automatically populating the biomimicry taxonomy for scalable systematic biologically-inspired design. In Proceedings of ASME 2012 International Design Engineering Technical Conferences and Computers and Information in Engineering Conference, August 12-15, Chicago, Illinois, USA. American Society of Mechanical Engineers, New York, NY, USA, pp. 383-391.

60. Cheong $\mathrm{H}$ and Shu LH (2012) Automatic extraction of causally related functions from natural-language text for biomimetic design. Proceedings of ASME 2012 International Design Engineering Technical Conferences and Computers and Information in Engineering Conference, August 12-15, Chicago, Illinois, USA. American Society of Mechanical Engineers, New York, NY, USA, pp. 373-382. 
61. Design Engineering Lab (2016) http://design.engr.oregonstate.edu/ (accessed 27/03/2016).

62. Design Engineering Lab (2016) http://www.designengineeringlab.org (accessed 23/12/2016)

63. Benyus JM (2008) Biomimicry: Innovation Inspired by Nature. Harper Perennial, New York, NY, USA.

64. Vattam SS and Goel AK (2011) Foraging for inspiration: understanding and supporting the online information seeking practices of biologically inspired designers. Proceedings of ASME 2011 International Design Engineering Technical Conferences and Computers and Information in Engineering Conference, August 28-31, Washington, DC, USA. American Society of Mechanical Engineers, New York, NY, USA, pp. 177-186.

65. Design \& Intelligence Laboratory (2016) Biologue. Design \& Intelligence Laboratory, Georgia Institute of Technology, Atlanta, GA, USA. See http://home.cc.gatech.edu/dil/336 (accessed 27/03/2016).

66. Vincent JFV (2014) An ontology of biomimetics. In Biologically Inspired Design (Goel AK, McAdams DA and Stone RB (eds)) Springer, London, UK, pp. 269-285.

67. bionicinspiration.org (2016) http://bionicinspiration.org/ (accessed 03/27/2016)

68. Kozaki K and Mizoguchi R (2014) An ontology explorer for biomimetics database. In ISWC-PD'14 Proceedings of the 2014 International Conference on Posters \& Demonstrations Track, Riva del Garda, Italy (Horridge M, Rospocher M and van Ossenbruggen J (eds)). CEUR-WS.org, Aachen, Germany, vol. 1272, pp. 469-472.

69. Kozaki K (2016) http://biomimetics.hozo.jp/ontology_db.html (accessed 27/03/2016)

70. Rosa F, Cascini G and Baldussu A (2015) Uno-BID: unified ontology for causal-function modeling in biologically inspired design. International Journal of Design Creativity and Innovation 3(3-4): 177-210

71. Kaiser MK, Hashemi Farzaneh $\mathrm{H}$ and Lindemann U (2014) Bioscrabble - the role of different types of search terms when searching for biological inspiration in biological research articles. In DS 77: Proceedings of the DESIGN 2014 13th International Design Conference (Marjanović D, Štorga M, Pavković N and Bojčetić N (eds)). The Design Society, Glasgow, UK, pp. 241-250.

72. Arlitt RM, Immel SR, Berthelsdorf FA and Stone RB (2014) The biology phenomenon categorizer: a human computation framework in support of biologically inspired design. Journal of Mechanical Design 136(11): 111105

73. Williams ML, Ertas A and Tate D (2014) Using stochastic multicriteria acceptability analysis in biologically inspired design as a multidisciplinary tool to assess biology-to-engineering transfer risk for candidate analogs. Journal of Mechanical Design 136(11): 111107.

74. Helfman Cohen Y, Reich Y and Greenberg S (2014) Biomimetics: structure-function patterns approach. Journal of Mechanical Design 136(11): 111108

75. Goel AK, Zhang G, Wiltgen B et al. (2015) On the benefits of digital libraries of case studies of analogical design: documentation, access, analysis, and learning. Artificial Intelligence for Engineering Design, Analysis and Manufacturing 29(2): 215-227.

76. Karim Network (2016) Introduction to Nature Inspired Solutions. Paris Region Enterprise, Paris, France. See http://www.karimnetwork. com/wp-content/uploads/2015/02/Guide Biomimicry online.pdf (accessed 23/12/2016)

77. Karim Network (2016) European Network for Responsible Innovation and Technology Transfer. Karim Network. See http://www. karimnetwork.com/ (accessed 27/03/2016).

78. ResilieNtWeb (2016) ResilieNtWeb: Innovate for a Sustainable Business. ResilieNtWeb, Brussels, Belgium. See http://resilientweb.eu/en/ (accessed 27/03/2016)

79. Freitas Salgueiredo C and Hatchuel A (2014) Modeling biologically inspired design with the C-K design theory. In DS 77: Proceedings of the DESIGN 2014 13th International Design Conference (Marjanović
D, Storga M, Pavković N and Bojčetić N (eds)). The Design Society, Glasgow, UK, pp. 23-32.

80. Reap J and Bras B (2014) A method of finding biologically inspired guidelines for environmentally benign design and manufacturing. Journal of Mechanical Design 136(11): 111110.

81. Vandevenne D, Caicedo J, Verhaegen PA, Dewulf S and Duflou JR (2013) Webcrawling for a biological strategy corpus to support biologically-inspired design. In CIRP Design 2012 (Chakrabarti A (ed.)). Springer, London, UK, pp. 83-92.

82. Snell-Rood E (2016) Interdisciplinarity: bring biologists into biomimetics. Nature 529(7586): 277-278.

83. Bar-Cohen Y (2006) Biomimetics - using nature to inspire human innovation. Bioinspiration \& Biomimetics 1(1): P1-P12.

84. Cheong H, Hallihan G and Shu LH (2014) Understanding analogical reasoning in biomimetic design: an inductive approach. In Design Computing and Cognition '12 (Gero JS (ed.)). Springer, Dordrecht, the Netherlands, pp. 21-39.

85. Hoeller N, Salustri F, DeLuca D et al. (2007) Patterns from nature. Proceedings of the Society for Experimental Mechanics Annual Conference and Exposition on Experimental and Applied Mechanics, Springfield, MA, USA, pp. 4-6.

86. Yen J and Weissburg M (2007) Perspectives on biologically inspired design: introduction to the collected contributions. Bioinspiration \& Biomimetics 2(4).

87. Speck T and Speck O (2008) Process sequences in biomimetic research. In Design and Nature IV - Comparing Design in Nature with Science and Engineering (Brebbia CA (ed.)). WIT Press, Southampton, UK, vol. I, pp. 3-11.

88. De Pauw I, Kandachar P, Karana E, Peck D and Wever R (2010) Nature inspired design: strategies towards sustainability. Knowledge Collaboration \& Learning for Sustainable Innovation: 14th European Roundtable on Sustainable Consumption and Production (ERSCP) Conference and the 6th Environmental Management for Sustainable Universities (EMSU) Conference, Delft, the Netherlands, 25-29 October.

89. Reap J, Baumeister D and Bras B (2005) Holism, biomimicry and sustainable engineering. Proceedings of ASME 2005 International Mechanical Engineering Congress and Exposition, November 5-11, Orlando, Florida, USA. American Society of Mechanical Engineers, New York, NY, USA, vol. 2005, pp. 423-431.

90. Mead TL (2014) Biologically-inspired management innovations. Proceedings of the XXV ISPIM Conference 2014, Dublin, Ireland, 8-11 June.

91. Antony F, Grießhammer R, Speck T and Speck O (2014) Sustainability assessment of a lightweight biomimetic ceiling structure. Bioinspiration \& Biomimetics 9(1): 016013.

92. Fayemi PE, Wanieck K, Zollfrank C, Maranzana N and Aoussat A (2016) Biomimetics: process, tools and practice. Bioinspiration \& Biomimetics (in press).

\section{How can you contribute?}

To discuss this paper, please submit up to 500 words to the journal office at journal@ice.org.uk. Your contribution will be forwarded to the author(s) for a reply and, if considered appropriate by the editor-in-chief, it will be published as a discussion in a future issue of the journal.

ICE Science journals rely entirely on contributions from the field of materials science and engineering. Information about how to submit your paper online is available at www.icevirtuallibrary.com/page/authors, where you will also find detailed author guidelines. 